\title{
Accelerating information of tsunami disaster using early warning system (EWS) Devices: smart solution for communication, navigation and surveillance due to tidal sea level
}

\author{
Nurhadi Santosa ${ }^{1 *}$, Nadjadji Anwar ${ }^{2}$, Bangun Muljo Sukojo ${ }^{3}$, and Wesam Al Madhoun ${ }^{4}$ \\ ${ }^{1}$ Doctoral Student of Civil Engineering Department, ITS Surabaya. \\ ${ }^{2}$ Professor of Civil Engineering Department, ITS Surabaya \\ ${ }^{3}$ Professor of Geomatics Engineering Department, ITS Surabaya \\ ${ }^{4}$ Dean and Doctor of Engineering Faculty Gaza University
}

\begin{abstract}
Oneof the important aspects in reducing Tsunami Risk is understanding Natural Hazards. The loss of INA TEWS equipment worth hundreds of billions of rupiah and the occurrence of the Tsunami in Aceh and other parts of Indonesia are warnings that our society needs the help of effective early warning tools at affordable prices. Using this device will make it easier for the community to monitor natural events from the field and reduce disaster risk. Currently the government has purchased hundreds of units of JRC-UNESCO products, namely IDSL (Inexpensive Device for Sea Level), but this device takes 21 minutes of information to reach the community. Therefore, a new device that has been prepared is needed. (FIDELA EARLY WARNING SYSTEM/FEWS) is a tool that involves the Equipment sector, Operations sector and Community sector. The results shows that this device is that the time for sending information to the public is only 5 minutes.
\end{abstract}

\section{Introduction}

Head of the data, Information and Public Relations Center of the National Disaster Management Agency (BNPB) Sutopo Purwo Nugroho revealed that the death toll was in Pandeglang, Serang, South Lampung, Pesawaran, and the Tanggamus area [3]. The large number of victims due to the tsunami was a result of the vulnerability of early detection. The latest update from Wartakotalive obtained from the BNPB Data and Information Center at the disaster site revealed that 281 people died, 1,1016 people were injured, 57 people were missing, 11687 people were displaced as shown in Fig. 1.

The same system, assisted by Germany which has been installed in West Sumatra since 2005, has also long been declared inoperative. Based on this experience, the use of tsunami early warning system technology in Indonesia must at least consider two important aspects, namely: low cost (installation and maintenance) and prevention of vandalism, in addition to technical aspects such as measurement accuracy and speed of warning delivery. early [1].

Based on data from the "Tsunami" Marine Knowledge Series, Directorate General of Marine Spatial Planning, Ministry of Marine Affairs and Fisheries, from 1964 to 2010 there were 23 tsunamis.
The 23 Tsunamis were

1. Flores Tsunami in 1961

The Flores Tsunami was caused by an earthquake at the epicenter 8.2 latitude, 122 east longitudes. There is no record of the scale of the earthquake that caused the tsunami, including the height of the tsunami and the number of fatalities.

2. Sumatra Tsunami in 1964

The tsunami was caused by an earthquake at the epicenter of 5.8 latitude, 95.6 east longitude, with a total of 110 people killed and 479 people injured.

3. Seram Tsunami - Maluku in 1965

This tsunami was caused by an earthquake at the epicenter of 2.4 latitude, 126 east longitude. The magnitude scale of the earthquake was $7.5 \mathrm{Sr}$, the tsunami height was 4 meters, and 71 people died.

4. Tinabung Tsunami - Sulawesi in 1967

The tsuami occurred as a result of an earthquake with an epicenter of 3.7 latitude, 119.3 east longitude with a magnitude of 5.8 that killed 58 people.

5. Tambu Tsunami - Sulawesi in 1968

The Tambu tsunami was caused by an earthquake with a magnitude of 7.4 on the Richter scale with an epicenter of 0.7 latitude, 119.7 east longitude. The earthquake caused a tsunami with a height of 10 meters and killed 200 people.

6. Majene Tsunami - Sulawesi in 1969

* Corresponding author: nurhadisantosa2000@gmail.com 
This tsunami was triggered by an earthquake measuring $6.9 \mathrm{Sr}$ at the epicenter 3.1 latitude, 118.8 east longitude with a tsunami height of 10 meters which killed 64 people.

7. Sumba Tsunami in 1977

Triggered by an earthquake measuring 8 on the Richter scale with an epicenter of 11.1 South Latitude, 118.5 East Longitude. The earthquake triggered a tsunami as high as 15 meters and 189 people died.

8. NTT Tsunami, Flores, Atauro Island in 1977

The NTT tsunami was triggered by an earthquake at the epicenter of 8 South Latitude, 125.3 East Longitude. There is no record of the magnitude scale of the earthquake that triggered this tsunami, the height of the tsunami, and the number of victims.

9. NTB Tsunami, Bali, Lombok, Sumbawa in1979

This tsunami was caused by an earthquake that occurred at 8.4 latitude, 115.9 east longitude, but there is no information on the scale of the earthquake and the height that occurred. However, the Flores tsunami killed 27 people and injured 200.

10. Larantuka Tsunami in 1982

The tsunami was caused by an earthquake at the epicenter of 8.4 South Latitude, 123 East Longitude with an earthquake scale of 5.9. The Larantuka tsunami killed 13 people but it is not known how high the tsunami was.

11. NTT Tsunami, East Flores, Pantar Island in 1987 The NTT tsunami in 1987 was triggered by an earthquake at the epicenter of 8.4 latitude and 124.3 east longitude. The scale of the earthquake and its height are unknown but the NTT tsunami killed 83 people and injured 108 people.

12. NTT Tsunami, Alor Island in 1989

The NTT tsunami in 1989 was caused by an earthquake at the epicenter. The tsunami natural disaster killed 7 people. The author did not find any reference indicating the magnitude scale of the earthquake and tsunami height that occurred on Alor Island in 1989.

13. Flores Tsunami in 1992

The Flores tsunami was the worst tragedy before the Aceh tsunami in 2004. This tsunami was triggered by an earthquake centered at 8.5 latitude, 121.9 east longitude with an earthquake scale of 7.5. The tsunami was recorded as high as 26 meters and killed 2,100 people in Flores.

14. Banyuwangi Tsunami, East Java in 1994

The Banyuwangi tsunami in 1994 was caused by an earthquake with a scale of 6.8 at the epicenter of 10.7 latitude, 113.1 east longitude. The tsunami generated by this earthquake was 14 meters high and killed as many as 208 people.
15. Palu Tsunami, Central Sulawesi in 1996

The Palu Tsunami was triggered by an earthquake with a magnitude of 7.7 which caused a tsunami with a height of 6 meters and killed 68 people.

16. Biak Tsunami, Papua in 1996

The Biak Tsunami in 1996 was caused by an earthquake with a magnitude of 8 at the epicenter 0.5 latitude, 136 east longitudes. The Biak tsunami was estimated to be 12 meters high and killed 160 people.

17. Taliabu Tsunami, Maluku in 1998

The Taliabu Tsunami in 1998 was estimated to be 3 meters high and killed 34 people. The Taliabu tsunami was caused by an earthquake with a magnitude of 7.7 at the epicenter of 2 South Latitude, 124.8 East Longitude.

18. Banggai Tsunami, Central Sulawesi in 2000

There is no information on the scale of the earthquake and the height of the Banggai tsunami in 2000. However, the Banggai tsunami killed 4 people and the tsunami was caused by an earthquake at the epicenter of 1.1 latitude and 123.5 east longitude.

19. Aceh Tsunami in 2004

The Aceh Tsunami is the largest and the most destructive in the $21 \mathrm{st}$ century which killed approximately 250,000 people. The Aceh tsunami was caused by an earthquake with a magnitude of $9.2 \mathrm{Mw}$ and triggered a tsunami as high as 34.5 meters on several beaches in Aceh. The epicenter of the earthquake that triggered the Aceh Tsunami was at the epicenter of 3.3 north latitude and 95.8 east longitude.

20. Nias Tsunami in 2005

The Nias tsunami was triggered by an earthquake with a magnitude of 8 at the epicenter of 2 North Latitude, 97.8 East Longitude. The tsunami caused by this earthquake was 3.5 meters high and no one died.

21. Pangandaran Tsunami in 2006

The Pangandaran tsunami in 2006 was triggered by an earthquake with a magnitude of 7.7 at the epicenter of 3.3 latitude and 107.9 east longitude. The 8.25-meter high Pangandaran tsunami killed 668 people.

22. Bengkulu Tsunami in 2007

The Bengkulu tsunami in 2007 with a height of 3.8 meters was caused by an earthquake with a scale of 8.4 at the epicenter at 3.7 latitude and 101 east longitudes. The Bengkulu tsunami did not cause any casualties.

23. Mentawai Tsunami in 2010

The Mentawai tsunami in 2010 was caused by an earthquake with a scale of 7.2 at the epicenter of 3.6 latitude and 99.93 east longitude. The Mentawai Tsunami killed 413 people and injured 448 people. The height of the Mentawai Tsunami is estimated to be around 7 meters. 


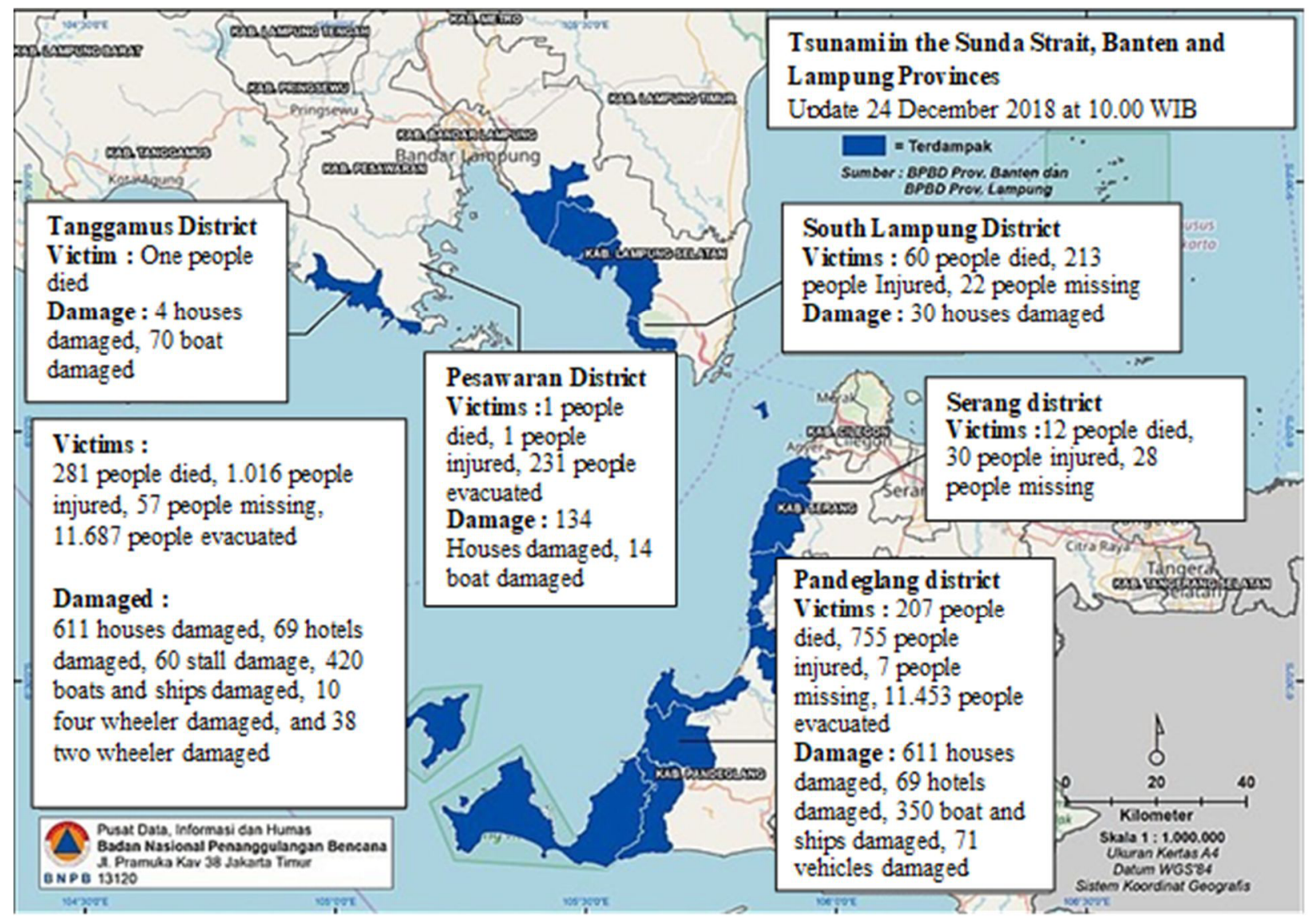

Fig. 1. Map of the Sunda Strait and its surroundings, as well as the tsunami disaster area marked in blue

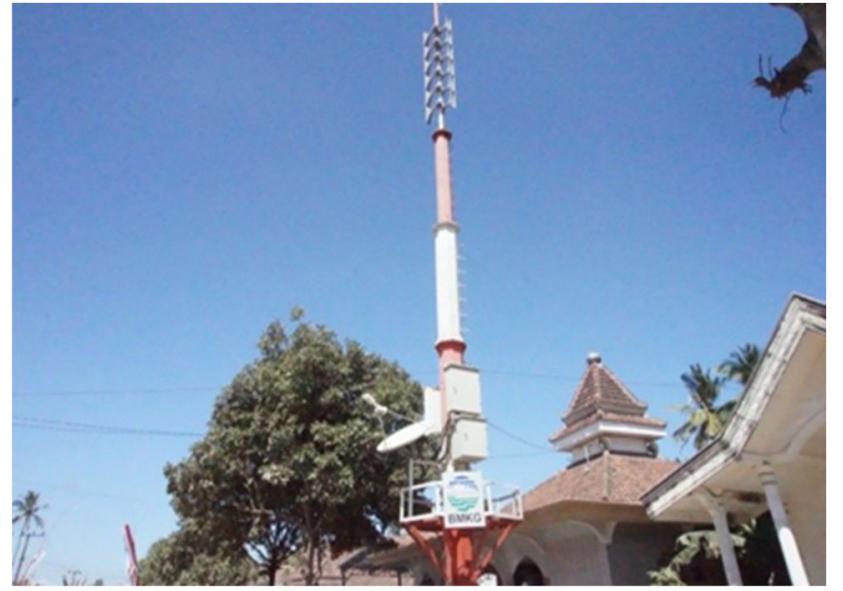

Fig. 2. Out-of validity-date Early warning system devices.

In addition to the above tools, the Joint Research Centre (JRC) in collaboration with the Indonesian Tsunami Society, the Marine Research Center of the Ministry of Marine Affairs and Fisheries (KKP) and the Indonesian Meteorology, Climatology and Geophysics Agency (BMKG) has also installed equipment. This collaboration has been carried out since December 2018 in order to design and implement a new Emergency System.

This new system will adopt the Inexpensive Device for Sea Level Monitoring (IDSL) instrument developed by JRC to monitor in real time at sea level and provide communication via email, SMS alerts, CCTV images and information about potential Tsunami events (see Fig. 3).

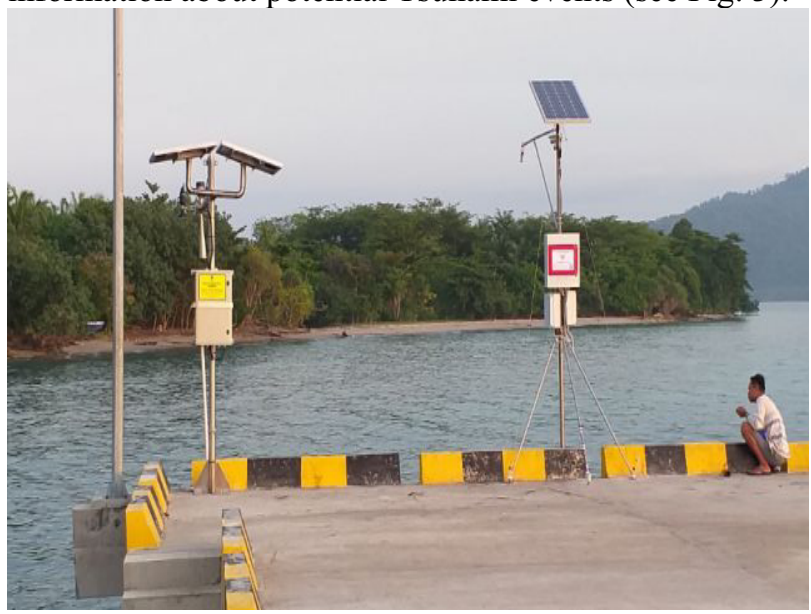

Fig. 3. On the left is the BIG Tide Gauge installation and on the right is IDSL. Both are in Sebesi Harbor.

Example of time calculation analysis when using the IDSL system:

a. There was a landslide on Mount Anak Krakatau

b. 1 minute was received at Sabesi Island IDSL.

c. 5 minutes of data was received and processed in the central TAD Server.

d. 5 minutes to make a decision for the authorities.

e. 5 minutes to contact the relevant agencies. 
f. 5 minutes sounding the siren.

g. Total 21 minutes lost.

h. Sirens can only reach a maximum of $2.5 \mathrm{~km}$ and are installed at only a few points from the need for a beach length of several hundred $\mathrm{km}$.

In the implementation of this smart device system, GAP ANALYSIS is carried out as follows:

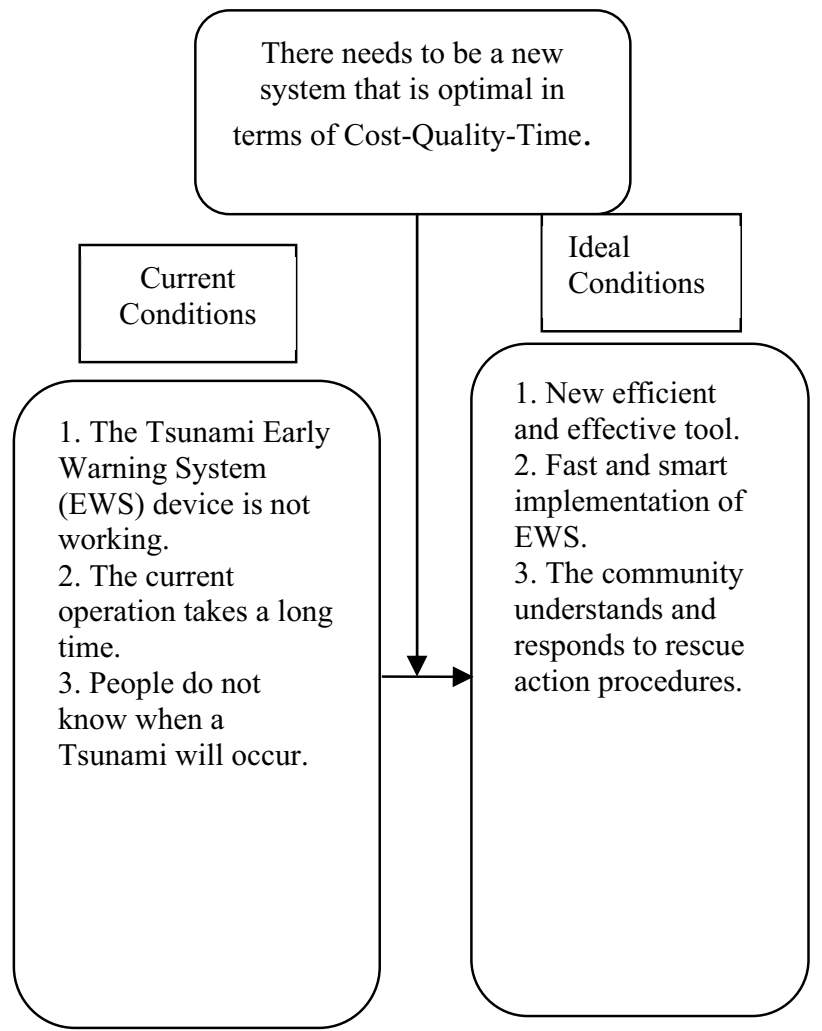

Fig. 4. Gap Analysis

Currently the government has purchased hundreds of units IDSL (Inexpensive Device for Sea Level), but this device takes 21 minutes of information to reach the community. Therefore, a new device is needed. The device is a system tool that involves the Equipment sector, Operations sector and Community sector. The expected result of this device is that the time for sending information to the public is only a few minutes

\section{Methodology}

\subsection{Materials}

Tsunami events occur when tides occur abnormally. Tsunamis are sea waves that are generated as a result of impulsive disturbance on the ocean floor. This impulsive disturbance occurs as a result of sudden changes in the geological structure of the seabed in either a vertical or horizontal direction [8] This in monitoring Tsunami is much data needed, in this case only looking at data from abnormally tidal.

To ensure this abnormal tidal event also needs to be proven in real live and real time using three parts of equipment, namely Transmitter, Main Receiver and Receiver. Transmitter consists of Tidal sensor pipe, 2-unit camera CCTV (one to monitor Tidal and other to monitor Coastal situation), radio communication, lightning rod, software and hardware to communicate between Transmitter and Main Receiver. These communication use internet facilities.

Main Receiver consists of LCD Monitor, Main Receiver software and Hardware, siren, speaker, microphone (to give a message and announcement from the Authority to many receivers contacted), lightning rod. Main internet is put on here to communicate and to spread internet network to receivers and transmitters. The Device are used for long range communication with up to $30 \mathrm{~km}$ line of sight. This Main Receiver received warning information from Transmitter that automatically send warning siren to Main Receiver, while the Authority make decision to turn on all of sirens in Receiver areas.

Receiver consists of unit receiver software and hardware, siren, speaker, lightning rod. These devices are placed in remote or rural place with supply internet from Main Receiver and power supply that can use from solar panel or State Electricity (PLN).

\subsection{Method}

In general, Accelerating Information of Tsunami Disaster Using Early Warning System (EWS) Devices: Smart Solution for Communication, Navigation and Surveillance Due to Tidal Sea Level at sea in this implementation consists of 3 aspects that were carried out, namely:

$\begin{array}{ll}\text { - } & \text { Tools. } \\ \text { - Operational. } \\ \text { - Community. }\end{array}$

The three optimization variables are in terms of cost, quality, and quality of data calculations.

Implementation Stages

\section{Result and Discussion}

To obtain warning information on changes in sea level, the following steps are needed, namely measuring sea level accurately, as close as possible to the source of the tsunami later. Fast data transmission of measurement location and presence of Software to analyze in real time and detect level changes, and provide warning and recheck data (CCTV images). Then the authorities decided to issue a warning to the beach location and activation of the siren system.

Sea level measurements are placed as close as possible to the source of the Tsunami so that the Government should also install at least every sub-district along the Coastal Coast that is prone to Tsunami and add loudspeakers in each community group. This can be done if the proposed cost for the device is very affordable for the parties concerned. 


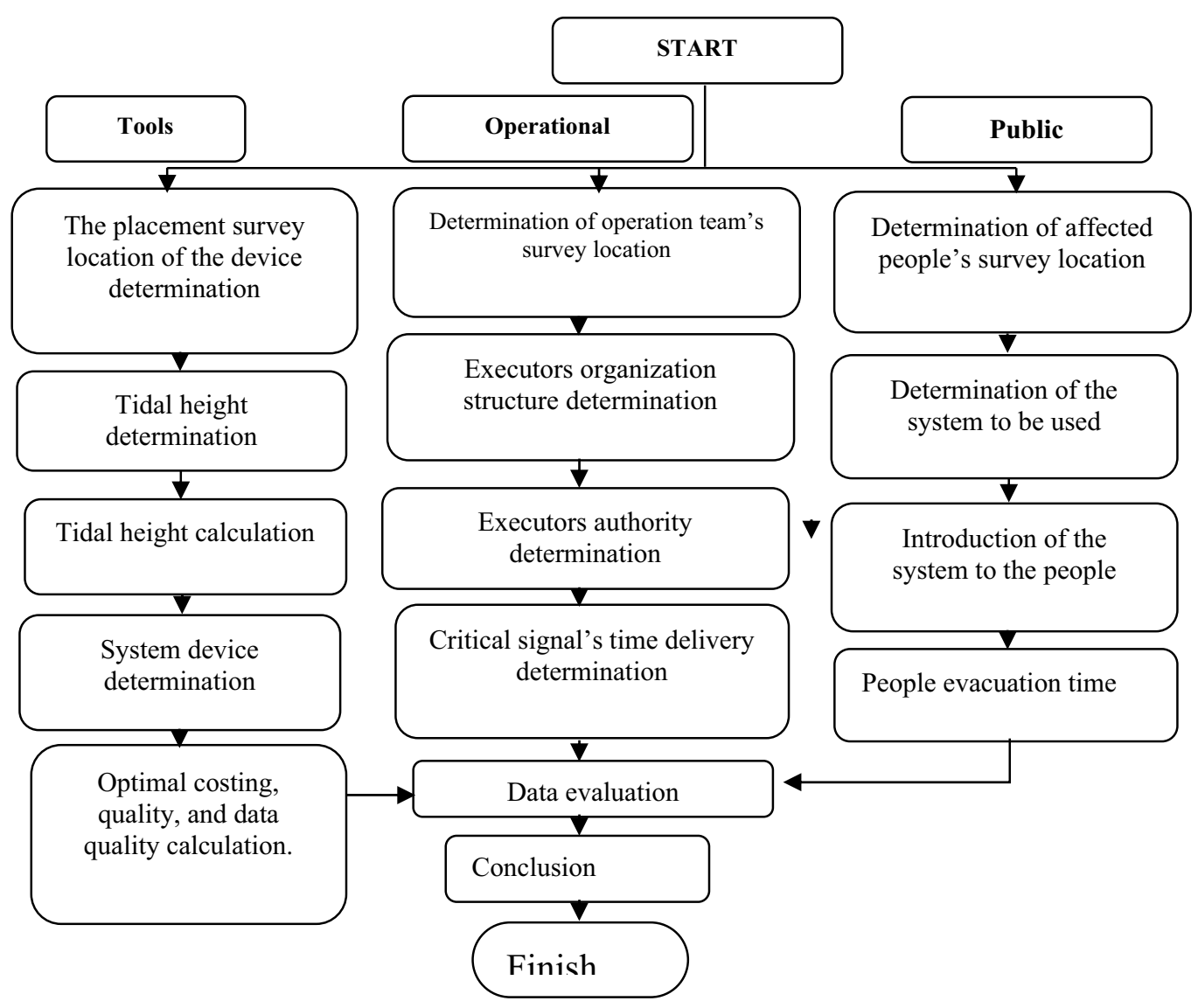

Fig. 5. Implementation Stages

Data transmission from the Measurement location must be sent rapidly. Of course, this cannot be done through a long bureaucratic path because it can hinder decision makers in providing information to the public.

Today's software is essential for processing data in real time and detecting level changes and also providing Alert signals to connected points.

In monitoring tsunami events, apart from tidal information, real information is needed in the form of reexamination through CCTV, so that there are clear signs of an impending tsunami.

Given the current tsunami incident, the decision of the authorities to issue warnings to coastal locations needs to be ready 24 hours to monitor tsunami events in their environment.

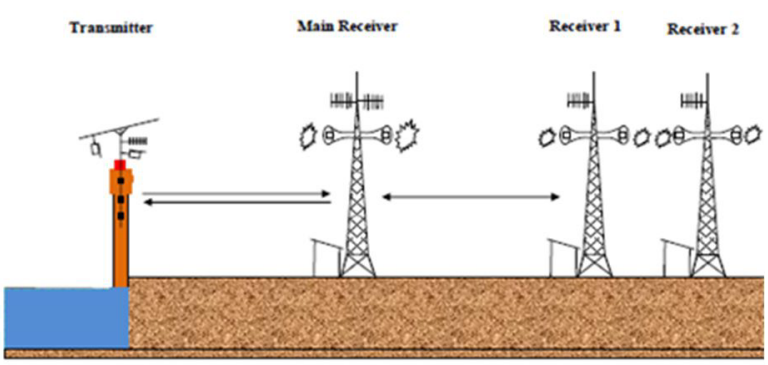

Fig. 6. Connections between the Main Receiver Transmitter and multiple receivers in remote areas.

The activation of sirens is the main thing in this early warning system and needs to be distributed evenly to remote areas prone to tsunamis, if necessary, using mosque loudspeakers that can be installed in this device system is a fairly efficient step as shown in Fig. 6.

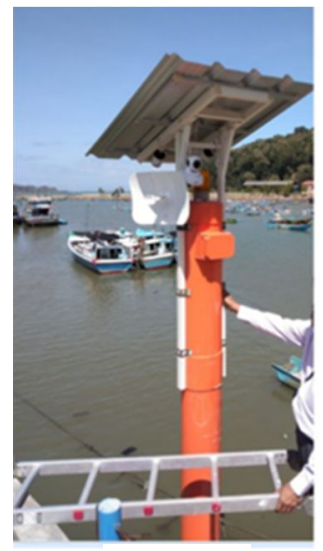

a.

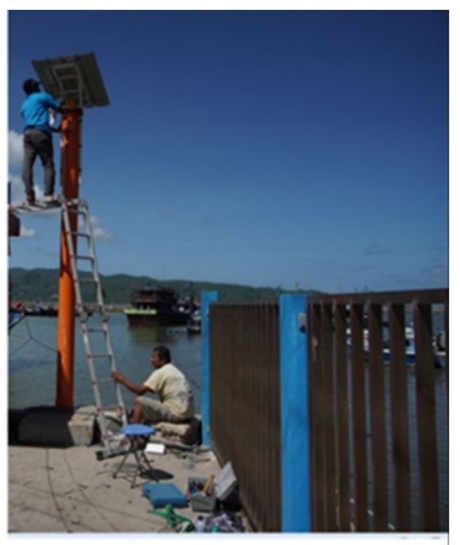

b.
Fig. 7. Fidela Tsunami Early Warning System in Tamperan Harbour Pacitan.

Transmitter is a Tidal Monitoring System Device that can provide real time information in the form of routine and abnormal tidal events and can provide visualization in the form of images or videos in real time using internet facilities.

The Main Receiver functions to receive data from the Transmitter and is read by the relevant agency Personnel Equipment to sound an Early Warning Signal to all Receivers in all remote tsunami-prone areas. 
Receivers in the form of loudspeakers and sirens are widely available at residential corner points or at Village Halls, and others.

The image is taken from a system device that has been created based on a patent submitted by the ITS university DUDI Partner team, namely LENUS AEROSPACE INDONESIA with the FIDELA TSUNAMI EARLY WARNING SYSTEM (FTEWS) device which is currently operating at Tamperan Beach, Pacitan Fig. 7. with inexpensive devices around $\$ 1.600$ for Server. This device can cut red tape to only 5 minutes compared to IDSL which takes 20 minutes.

\section{Conclusion}

The discussion shows that time wasted when the Tsunami incident been captured by receiving stations on the ground and transmitted to the community in an incomplete way because the recipients of siren information were only in the nearest location (maximum $2,5 \mathrm{~km}$ ) to the siren. Consequently, there is a need for a device that can cut bureaucratic lines and increase sirens to remote areas at an affordable cost for the community. Therefore, it is recommended to use Fidela Early Warning System devices than can cut red tape to only 5 minutes and this are inexpensive devices.

In the future, to improve the system to be integrated in the System Equipment which involves the Equipment sector, Operations sector and the community sector. The expected result of this device system is that the delivery time of information to the community is only a few minutes and how they take care about it.

\section{References}

1. T. Solihuddin, H. L. Salim, S. Husrin, A. Daulat, D. Purbani. The Impact of the Sunda Strait Tsunami in Banten Province and its Mitigation Efforts. Segara Journal , 15-28 (2020)

2. Directorate General of Marine Spatial Management, Ministry of Marine Affairs and Fisheries, Marine Knowledge Series. Tsunami, (2017)

3. Center for Information and Public Relations of the National Disaster Management Agency. Tsunami of the Sunda Strait, Banten and Lampung Provinces, (2018)

4. Earthquake and Tsunami Center Deputy for Geophysics, Katalog Tsunami Indonesia , (2019)

5. A. Alessandro, The Inexpensive Device for Sea Level Measurements. Italy: EC-Joint Research Centre, (2015)

6. G. Alessandro, B. Danielle, Matteo.. IDSL Sea Level Measurement Devices. JRC Technical Report. (2016)

7. Santosa, Nurhadi. Fidela Tsunami Early Warning System (Ftews). Lenus Aerospace Indonesia, Presentation (Power Point Format) on Geofisika Institute Teknologi Sepuluh Nopember Surabaya. (2019)

8. BMKG. Tsunami Early Warning Service Guidebook for InaTEWS. (BMKG, Ed.) Indonesia. (2012) 